\title{
Erosion of the telomeric single-strand overhang at replicative senescence
}

\author{
Sheila A. Stewart ${ }^{1 \star}$, Ittai Ben-Porath ${ }^{1 \star}$, Vincent J. Carey ${ }^{2}$, Benjamin F. O’Connor ${ }^{1}$, William C. Hahn ${ }^{3}$ \\ \& Robert A. Weinberg ${ }^{1}$ \\ ${ }^{*}$ These authors contributed equally to this work.
}

Published online 24 March 2003; doi:10.1038/ng1127

Cultured primary human cells inevitably enter a state of replicative senescence for which the specific molecular trigger is unknown. We show that the single-strand telomeric overhang, a key component of telomere structure, is eroded at senescence. Expression of telomerase prevents overhang loss, suggesting that this enzyme prevents senescence by maintaining proper telomere structure. In contrast, progressive overhang loss occurs in cells that avoid senescence through the inactivation of p53 and $\mathrm{Rb}$, indicating that overhang erosion is the result of continuous cell division and not a consequence of senescence. We thus provide evidence for a specific molecular alteration in telomere structure at senescence and suggest that this change, rather than overall telomere length, serves to trigger this state.

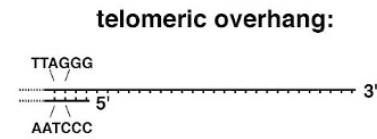

T-OLA:

hybridization
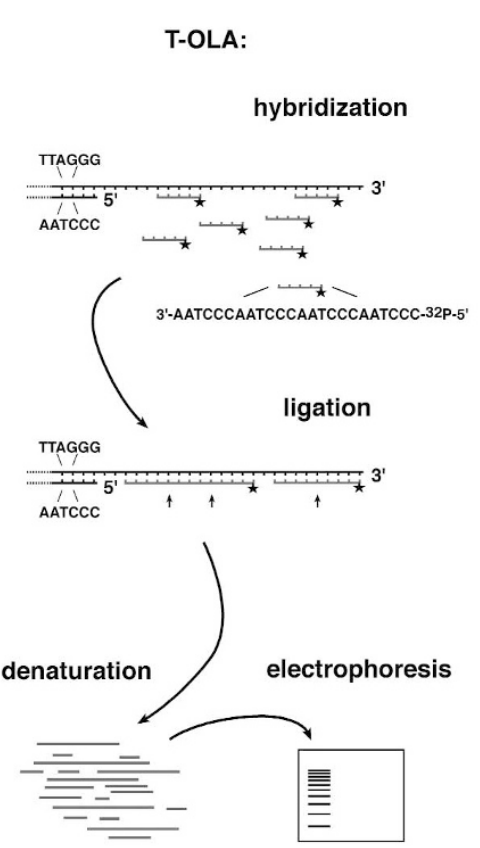

$b$

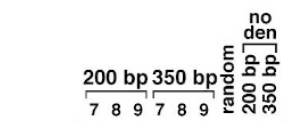

$312 \mathrm{nt}-$

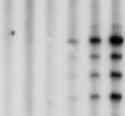

$168 \mathrm{nt}-$

Fig. 1 Measurement of the telomeric overhang using T-OLA. a, Schematic of the T-OLA method. Total genomic DNA is incubated with a radioactively labeled oligonucleotide of the sequence (CCCTAA) 4 . The oligonucleotide hybridizes to accessible G-rich telomeric overhangs. A ligase is added to the reaction, resulting in ligation of oligonucleotides that hybridized to adjacent positions along the overhang. This creates a collection of DNA fragments with sizes increasing by units of $24 \mathrm{nt}$ that are denatured and separated on a denaturing polyacrylamide gel. A population of telomeres carrying a longer average telomeric overhang length is expected to produce a stronger total T-OLA signal and a greater maximal product length. $\boldsymbol{b}$, T-OLA analysis of DNA fragments of 200 bp and 350 bp representing $10^{7}, 10^{8}$ and $10^{9}$ telomeres $(7,8,9)$ on the background of yeast genomic DNA. Analysis was also done with the same fragments in the absence of denaturation (no den) and with a 550-bp DNA fragment of random sequence (random). Product sizes are indicated. c, Analysis of genomic DNA from BJ foreskin fibroblasts at PD 40 pretreated with different enzymes as indicated. Ba/31 is a single-strand endonuclease, Exol is a single-strand $3^{\prime}$ specific exonuclease, ExollI degrades recessed and blunt 3' ends, T7 Gene 6 (T7G6) exonuclease degrades $5^{\prime}$ ends and Klenow DNA polymerase fills in 5' overhangs but not 3' overhangs. To verify equal amounts of input DNA, quantitative PCR was done on each T-OLA sample using primers directed against the genomic GAPD locus. Results of these PCR reactions are displayed below each T-OLA panel. $\boldsymbol{d}$, Analysis using oligonucleotides complementary to the G-rich strand (CCCTAA), to the C-rich strand (TTAGGG) or to neither (CCCTTA). e, T-OLA dose response using genomic DNA extracted from GM847 cells. 2, 4, 10 and $20 \mu \mathrm{g}$ of genomic DNA were analyzed.

${ }^{1}$ Whitehead Institute for Biomedical Research, Cambridge, Massachusetts 02142, USA. ${ }^{2}$ Channing Laboratory and ${ }^{3}$ Departments of Medical Oncology and Medicine, Dana-Farber Cancer Institute, Brigham and Women's Hospital, Harvard Medical School, Boston, Massachusetts 02115, USA. Correspondence should be addressed to R.A.W. (e-mail:weinberg@wi.mit.edu). 
Two main hypotheses have been proposed to explain the mechanism governing the replicative lifespan of primary human cells ${ }^{1-4}$. The first suggests that cultured cells suffer from physiologic stress and cumulative damage that ultimately trigger senescence. The second postulates that an intrinsic counting mechanism triggers senescence after a predetermined number of cell generations. The 'telomere length' hypothesis is based on the latter model and argues that the progressive telomere shortening that occurs during successive divisions induces senescence once telomeres erode to a critical length ${ }^{3,5}$. Consistent with this hypothesis, expression of telomerase, which halts telomere erosion, prevents senescence ${ }^{6,7}$.

Some important experimental findings are not easily explained by the telomere length hypothesis. In most senescent cells, telomeres are still quite long, often averaging 5-10 kilobases $(\mathrm{kb})^{5,8}$. There are many examples of cells that carry much shorter telomeres yet retain the ability to divide ${ }^{9-11}$. Thus, short telomeres per se are not incompatible with continued cellular division. Moreover, experimental acceleration of telomere shortening does not affect the onset of senescence ${ }^{12}$.

We speculated that another aspect of telomere structure, distinct from overall length, might govern the onset of senescence.
Telomeric DNA consists of a double-strand region composed of TTAGGG repeats, which terminates in a $3^{\prime}$ single-strand G-rich overhang (refs. 13-16; Fig. 1a). The telomeric overhang has been implicated as a critical component of telomere structure that is required for proper telomere function ${ }^{17-19}$. We therefore undertook to examine whether changes in the overhang occur during senescence.

To assess the length of the telomeric overhang, we used a recently developed method termed telomere-oligonucleotide ligation assay (T-OLA; ref. 20). In this assay, radiolabeled oligonucleotides complementary to the telomeric overhang are annealed to genomic DNA, ligated and then electrophoretically separated (Fig. 1a). The length of the ligation products and their radioactive intensity then provide an indication of the length of the overhangs present in the sample.

We carried out a series of control experiments to assess the accuracy and sensitivity of T-OLA. First, we denatured a known number of double-strand DNA molecules composed of 200 and 350 base pairs (bp) of tandem telomeric repeats and mixed these with yeast genomic DNA (serving as a surrogate for non-telomeric genomic DNA). T-OLA analysis of this reconstructed system $a$

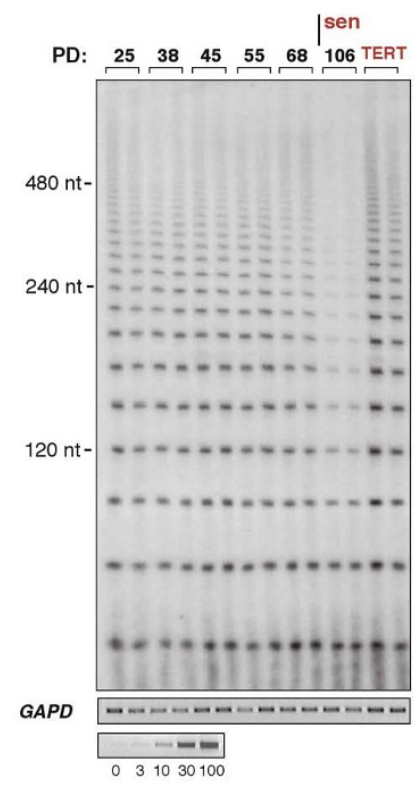

$e$

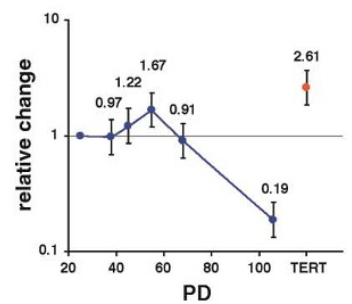

$b$
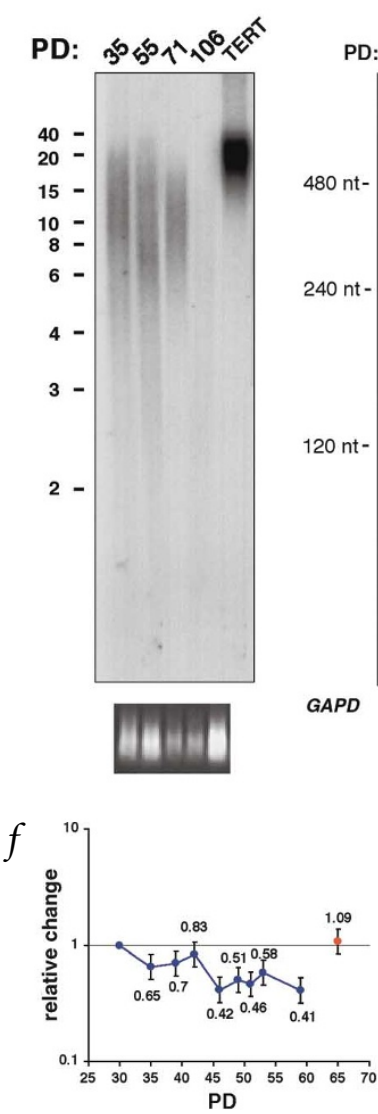

$c$

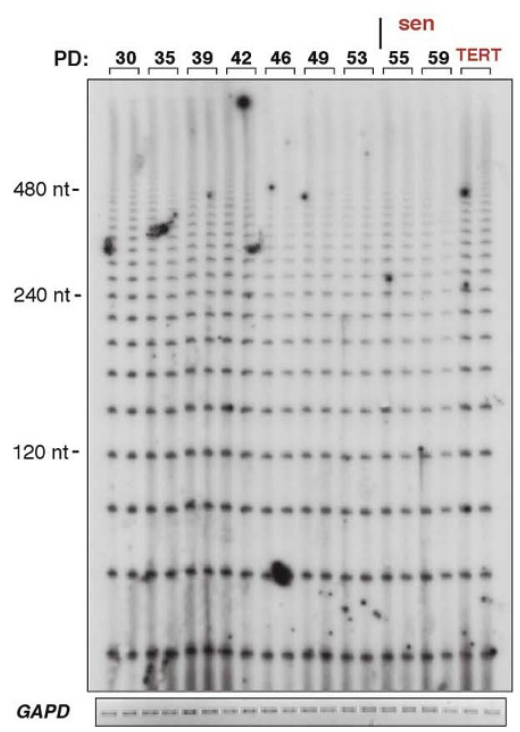

$g$

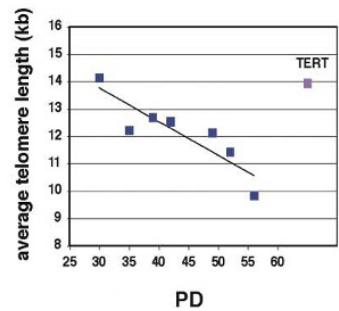

$d$
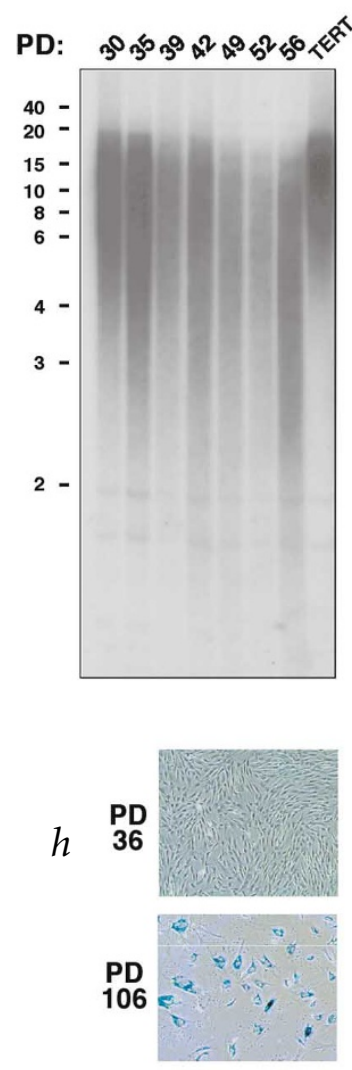

Fig. 2 Loss of the telomeric overhang at replicative senescence. a, T-OLA analysis of DNA from BJ fibroblasts at different PDs up to senescence (sen) and from BJ cells expressing ectopic TERT. All DNA samples were assayed in duplicate. Quantitative PCR of the GAPD locus done on each sample is displayed in the lower panel. Standards for PCR (0-100 ng of genomic template DNA) quantification are shown. $\boldsymbol{b}$, Non-denaturing TRF Southern-blot analysis of genomic DNA isolated from BJ cells at the indicated PD or from BJ cells expressing ectopic TERT. Signal intensity represents the amount of single-strand overhang available for hybridization, whereas migration sizes represent overall telomere length. Size markers (in kb) are indicated. Lower panel shows ethidium-bromide staining of the gel indicating relative DNA amounts loaded. $c$, T-OLA analysis of genomic DNA isolated from MRC5 fibroblasts at the indicated PD. $d$, Denaturing TRF Southern-blot analysis of genomic DNA from MRC5 cells at the indicated PD (due to denaturation, this figure represents overall telomere length and not overhang length). Size markers (in kb) are indicated. $e, f$, Densitometric analysis of T-OLA signal intensities in senescing BJ (e) and MRC5 ( $f$ ) cells. The geometric mean intensities of all detected T-OLA products in duplicate lanes were calculated and compared to the first sample. Estimates were transformed to relative changes. Error bars represent $95 \%$ confidence intervals. $\boldsymbol{g}$, Graphic representation of average telomere lengths shown in $d$. $\boldsymbol{h}$, Senescence-associated $\beta$-galactosidase staining of BJ fibroblasts at PD 36 and PD 106. 
Fig. 3 Loss of the telomeric overhang in cells expressing large T-antigen. a, TOLA analysis of BJ fibroblasts at PD 39 and of BJ fibroblasts expressing the SV40 large T-antigen (T-Ag) continuously passaged to PD 20, 27 and 44 after introduction of large T-antigen $(+20,+27,+44)$ and up to crisis (cri). Cells expressing TERT were also tested. Densitometric analysis is shown underneath each panel. b, Similar analysis of MRC5 cells at PD 30 and of MRC5 cells expressing the large T-antigen (T-Ag) continuously passaged to PD 20 after introduction of large Tantigen (+20) and up to crisis (cri). Cells expressing TERT were also tested.

yielded products with maximal lengths of 168 and 312 nucleotides (nt), respectively (Fig. $1 b$ ), indicating that the assay is sensitive enough to detect telomeres present in total genomic DNA and provides a reasonably accurate representation of overhang length. In the absence of template denaturation, we detected only a faint signal, and a template with a randomly chosen sequence produced no signal (Fig. $1 b$ ).

We next treated genomic DNA samples from human BJ foreskin fibroblasts with various enzymes predicted to affect overhang length. We found that treatment with each of the enzymes affected T-OLA product length in the expected manner (Fig. 1c; see also ref. 20). Importantly, treatment with Bal31, a singlestrand specific endonuclease, or with ExoI, a single-strand specific exonuclease, resulted in loss of most T-OLA signal (Fig. 1c). An oligonucleotide carrying a mismatched telomeric sequence did not yield a T-OLA signal, and an oligonucleotide complementary to the C-rich strand produced only a faint signal (Fig. 1d). Finally, T-OLA signal intensities showed a near-linear response to increases in input genomic DNA (Fig. 1e). These experiments show that T-OLA detects the presence of $3^{\prime}$ singlestrand telomeric overhangs with high specificity and sensitivity.

We used T-OLA to examine the telomeric overhang in BJ fibroblasts grown in culture from an early passage until they reached senescence. By population doubling (PD) 80, the proliferation rate of these cells is greatly reduced, and by PD 100 virtually all cells become senescent, exhibiting a typical flat morphology and senescence-associated $\beta$-galactosidase activity (Fig. 2h). T-OLA done on DNA from early-passage BJ cells (PD 25) generated a ladder of products reaching a maximal detected length of $624 \mathrm{nt}$ (Fig. 2a). Previous reports have estimated that the overhang ranges from 50 to $400 \mathrm{nt}$ in various cell types including BJ fibroblasts ${ }^{13-16,20}$. Although most overhangs may be in this size range, T-OLA is probably sensitive enough to detect longer overhangs if they are present in the sample.

As BJ cells were passaged, T-OLA products remained constant in intensity and maximal length up to PD 68 (Fig. 2a). Notably, senescent BJ cells at PD 106 had markedly lower signal intensity, with products reaching a maximal detected length of only $384 \mathrm{nt}$ (Fig. 2a). Densitometric analysis indicated that the total signal intensity of T-OLA products in senescent cells dropped to $19 \%$ of that observed in young cells (Fig. $2 e$ ). Thus, both the maximal length and total signal intensity were lower in senescing BJ cells, indicating substantially shorter overhangs in these cells. We also examined the telomeric overhangs in BJ cells by an alternative method, non-denaturing telomeric restriction fragment (TRF) Southern blotting ${ }^{15}$. Similar to our results with T-OLA, we found that the telomeric overhang in senescent (PD 106) BJ cells was considerably shorter than that of younger cells (Fig. $2 b$ ).

We also carried out T-OLA analysis on an additional normal human cell line, MRC5 human lung fibroblasts. These cells enter senescence between PD 49 and PD 59. T-OLA analysis indicated that senescing MRC5 cells had much shorter telomeric overhangs (Fig. 2c,f), and this was also shown by non-denaturing TRF Southern-blot analysis (data not shown)

We observed that in both BJ and MRC5 cells, the T-OLA products of $120 \mathrm{nt}$ and longer were markedly less abundant in senescent
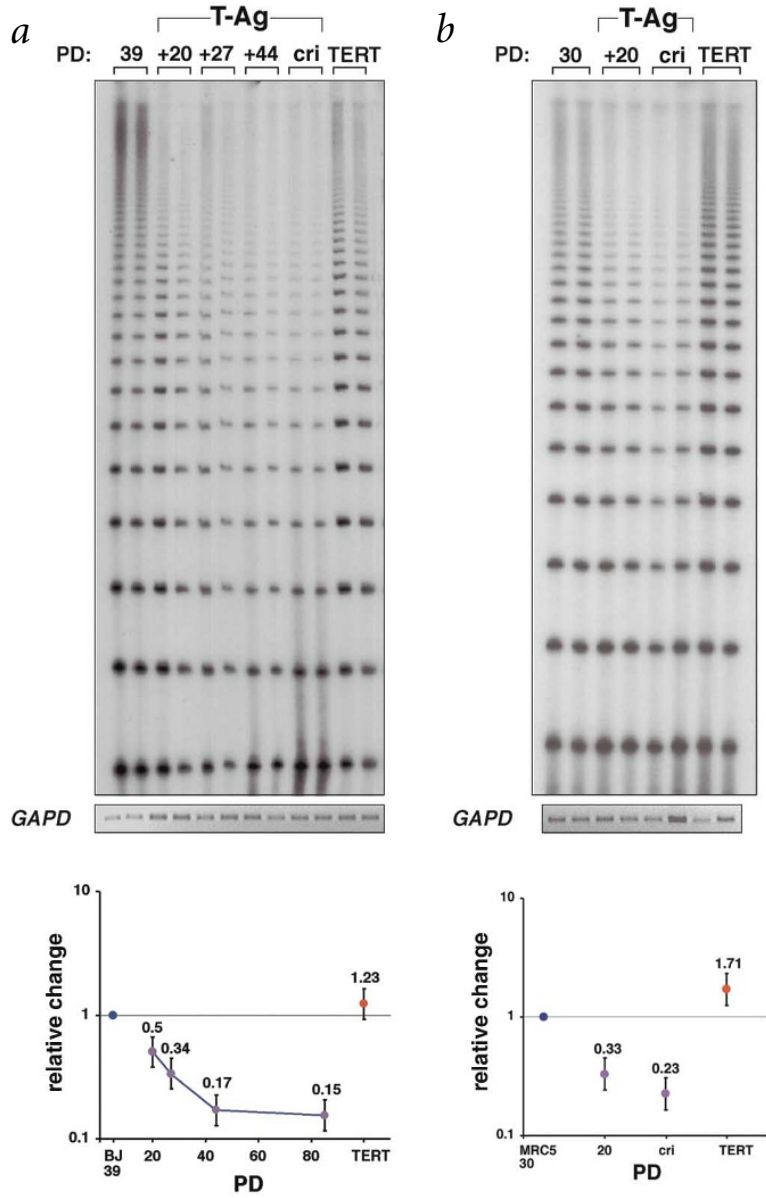

cells, whereas products of 48-96 nt remained nearly constant in intensity throughout the lifespan of the cells (Fig. $2 a, c$ ). Densitometric analysis indicated that in the senescent cells $65 \%$ of the signal intensity was observed in products $<120 \mathrm{nt}$, as compared with $37 \%$ in early passage cells. It has been shown that telomeres can exist in a 'T-loop' structure ${ }^{18}$. The formation of the T-loop depends on the presence of the telomeric overhang, which invades upstream double-strand telomeric DNA, and it has been suggested that at least $100 \mathrm{nt}$ of overhang participate in the formation of this structure ${ }^{18,21}$. Our data suggest that during senescence most overhangs drop below $100 \mathrm{nt}$, potentially disrupting the T-loop or another telomeric structure.

The kinetics of overhang loss differ from those of overall telomere shortening. Telomere shortening has been shown to occur at a constant rate of approximately $50-100$ bp per division in various cell types ${ }^{5,16,22}$. We observed this type of overall telomere shortening in both BJ (Fig. 2b) and MRC5 cells (Fig. 2d,g). In contrast, we found that telomeric overhang lengths remained constant during early passages and then dropped abruptly at senescence (Fig. 2e,f). This difference in kinetics indicates that overhang length is not a direct reflection of overall telomere length.

Ectopic expression of the catalytic subunit of telomerase (TERT) prevents senescence in many cell types ${ }^{6,7}$. Because telomerase adds telomeric repeats to the $3^{\prime}$ end of the telomere, it could directly extend the telomeric overhang ${ }^{23}$. We found that BJ and MRC5 cells overexpressing TERT carried telomeric overhangs similar in length to those present in early-passage cells, or, in some cases, longer (Fig. $2 a-c, e, f$ ). Thus, sequences added to the $3^{\prime}$ telomeric end by telomerase extend overall telomere length but also generate longer single-strand overhangs. We suggest that the means by which telomerase prevents 
entry to senescence is by maintaining telomeric overhang and, therefore, proper telomere structure, rather than by extending double-strand repeats.

It is possible that loss of the telomeric overhang is a consequence of the senescence program itself and, as such, does not have a causal role in inducing this state. To test this, we examined whether the telomeric overhang was lost in cells that bypass senescence after inactivation of the senescence effector proteins p53 and Rb, which is achieved by overexpression of the SV40 large T-antigen. Such cells continue to divide beyond the senescence point until they reach a second proliferative barrier termed crisis ${ }^{24}$. At crisis, the bulk of the double-strand telomeric DNA is lost, resulting in genomic catastrophe and massive cell death. BJ and MRC5 cells expressing large T-antigen were passaged beyond the point where they normally enter senescence and into crisis. Notably, the telomeric overhangs in these cells were progressively lost during propagation to an extent similar to that observed in senescent cells (Fig. $3 a, b)$. Thus, overhang loss seems to be a direct result of continued cellular division and not of the senescence program itself. Furthermore, the continued growth of cells lacking normal telomeric overhangs indicates that inactivation of the p53 and Rb pathways renders cells refractory to signals induced by telomeric overhang loss. The fraction of such cells in the population is thus allowed to progressively increase, explaining the progressive mode of overhang erosion that is observed by T-OLA in these cells. In a normal cell population, however, cells losing their overhangs will senesce and be eliminated from the population. Therefore, substantial $a$
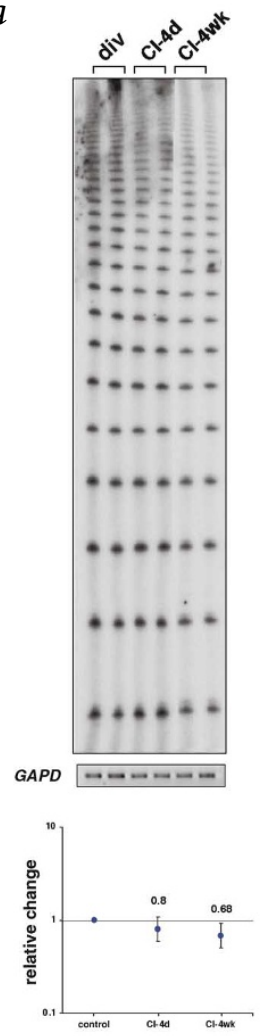

$b$
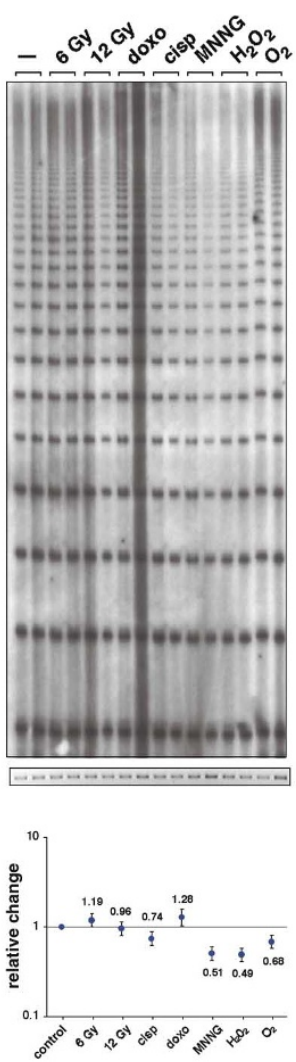

overhang loss is observed only when most of the cells in the population senesce.

To test whether the quiescent state of senescent cells contributes to overhang loss, we induced growth arrest in BJ fibroblasts by contact inhibition. T-OLA signal intensity in arrested cells was $80 \%$ of that in proliferating cells (Fig. $4 a$ ). When cells were held under these quiescent conditions for 4 weeks, we observed a slight further decrease in signal to $68 \%$ of that observed in proliferating cells (Fig. 4a). We conclude that the state of quiescence can contribute to a minor loss of telomeric overhang but cannot explain the substantial loss (to 19\%) observed in senescence (Fig 2e).

To determine whether overhang loss is a general cellular response to physiologic stress, we exposed BJ cells to DNA damage-inducing agents, to oxidative stress conditions or to metabolic stresses. Some treatments caused a considerable reduction in T-OLA signal, specifically methyl-nitro-nitroso-guanidine, hydrogen peroxide and cycloheximide (Fig. 4b,c). The former two have been suggested to specifically damage G-rich telomeric $\mathrm{DNA}^{25}$. None of the treatments reduced T-OLA signal to the same magnitude of the reduction observed in senescent BJ cells, indicating that loss of the telomeric overhang is not a general cellular response to physiologic stress. Instead, we suggest that certain physiologic stresses suffered by cells in culture provoke telomeric overhang loss; moreover, the erosion of the telomeric overhang observed during replicative senescence may be the consequence of the cumulative stress experienced by cells during extended culture in vitro.

Our results are the first iden-
$\mathcal{C}$
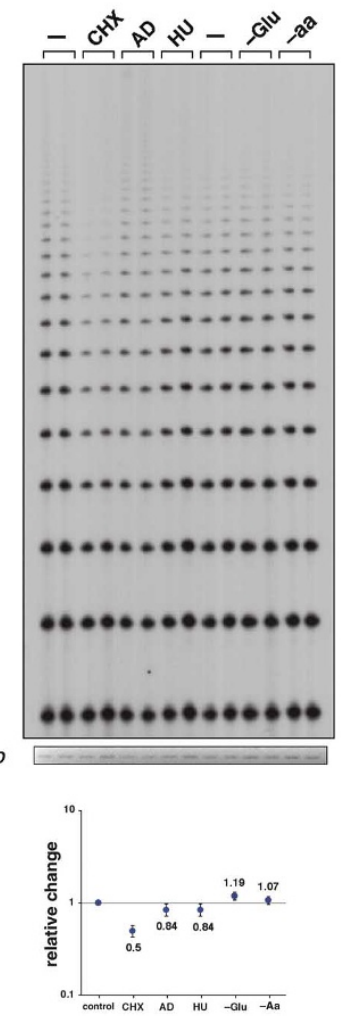

Fig. 4 Effect of growth arrest and physiologic stress on telomeric overhang length. a, T-OLA analysis of genomic DNA from dividing BJ fibroblasts (div) and from BJ cells arrested by contact inhibition for $4 \mathrm{~d}(\mathrm{Cl}-4 \mathrm{~d})$ or $4 \mathrm{wk}(\mathrm{Cl}-4 \mathrm{wk})$. $b$, Analysis of BJ fibroblasts exposed to the following genotoxic agents for $48 \mathrm{~h}$ : no treatment (-), $6 \mathrm{~Gy}$ and $12 \mathrm{~Gy} \gamma$-irradiation, doxorubicin (doxo), cisplatin (cisp), methyl-nitro-nitroso-guanidine (MNNG) or hydrogen peroxide $\left(\mathrm{H}_{2} \mathrm{O}_{2}\right)$. Cells were exposed to $40 \%$ oxygen $\left(\mathrm{O}_{2}\right)$ for 2 wk. c, Analysis of cells exposed to the following treatments for $48 \mathrm{~h}$ : no treatment $(-)$, cycloheximide (CHX), actinomycin D (AD) or hydroxyurea (HU). Cells grown in the absence of glucose (-Glu) or of the amino acids leucine and glutamine (-aa) were also analyzed. tification of a specific molecular alteration that occurs at the telomere in association with senescence. Previous studies have suggested that the telomeric overhang is an essential component of telomere structure $^{17-19}$, and we believe that its erosion reflects the disruption of this nucleoprotein structure. Accordingly, we propose that overhang loss, rather than shortening of overall telomere length, is the molecular signal that triggers senescence. Erosion of the telomeric overhang would be expected to cause collapse of a structure such as the T-loop, to affect telomerebinding proteins and to cause exposure or 'uncapping' of the telomere end ${ }^{17}$. Alternatively, disruption of the nucleoprotein structure could lead to exposure of the telomeric overhang and to its subsequent erosion. Each of these events could in turn cause the activation of the p53 and $\mathrm{Rb}$ pathways, leading to senescence. Our findings thus identify a potential molecular trigger for senescence and challenge the current paradigm that telomere shortening is the molecular clock that limits replicative lifespan. 


\section{Methods}

T-OLA analysis. We carried out the T-OLA assay as described ${ }^{20}$. Briefly, we extracted genomic DNA by standard cell lysis, proteinase K treatment, phenol and chloroform extraction and RNaseA treatment. We used $5 \mu \mathrm{g}$ of genomic DNA per assay in a $20-\mu \mathrm{l}$ reaction volume containing $0.5 \mathrm{pmol}^{32} \mathrm{P}$-end-labeled oligonucleotide of the sequence (CCCTAA) ${ }_{4}$ We used oligonucleotides of the sequence (TTAGGG) ${ }_{4}$ to detect the Crich strand and of the sequence (CCCTTA $)_{4}$ as a mismatch control. We carried out hybridization for $12-15 \mathrm{~h}$ at $50{ }^{\circ} \mathrm{C}$ followed by ligation using 20 units of Taq DNA ligase (New England Biolabs) at $50^{\circ} \mathrm{C}$ for $5 \mathrm{~h}$. After ligation, we precipitated and dried the reactions, resuspended products in water and denatured them in a formamide-based loading buffer. We separated products on $5 \%$ acrylamide, $6 \mathrm{M}$ urea gels. To ensure equal DNA loading of T-OLA gels, we used $10 \mathrm{ng}$ of every T-OLA sample as template for quantitative PCR reaction for the genomic GAPD gene. Primer sequences are available on request. In the reconstituted system, we used 2 20 or $200 \mathrm{pg}$ of a 200 -bp fragment or 5,50 or $500 \mathrm{pg}$ of a 350 -bp fragment, both containing telomeric repeats, as templates together with $5 \mu \mathrm{g}$ of $\mathrm{Sac}-$ charomyces cerevisiae genomic DNA. We carried out enzyme treatments of genomic DNA as follows: $0.25 \mu \mathrm{g} \mu \mathrm{l}^{-1}$ of genomic DNA was treated with 0.6 units $\mu \mathrm{l}^{-1}$ T7 Gene 6 exonuclease (Roche) for $25 \mathrm{~min}$ at $37^{\circ} \mathrm{C}$, with 0.3 units $\mu^{-1}$ Bal31 nuclease (New England Biolabs) for $25 \mathrm{~min}$ at $30^{\circ} \mathrm{C}$ or 1 unit $\mu \mathrm{l}^{-1}$ Exonuclease III (USB) for $30 \mathrm{~min}$ at $37^{\circ} \mathrm{C}$. We treated $0.05 \mu \mathrm{g} \mathrm{\mu \textrm {l } ^ { - 1 }}$ of genomic DNA with 1 unit $\mu l^{-1}$ Exonuclease I (USB) for $24 \mathrm{~h}$ at $37^{\circ} \mathrm{C}$ or 1 unit $\mu \mathrm{g}^{-1}$ Klenow DNA polymerase I (New England Biolabs) in the presence of $33 \mu \mathrm{M}$ dNTPs for $25 \mathrm{~min}$.

TRF Southern-blot analysis. We digested $3 \mu \mathrm{g}$ of total genomic DNA for $16 \mathrm{~h}$ with RsaI and Hinfl and separated it on a $0.7 \%$ Tris-borate-EDTA agarose gel. We then dried gels at $63{ }^{\circ} \mathrm{C}$ for $50 \mathrm{~min}$ and prehybridized them in $5 \times$ Denhardt's solution, $5 \times$ sodium chloride/sodium citrate buffer, $0.1 \%$ SDS and $20 \mathrm{mM} \mathrm{NaH}_{2} \mathrm{PO}_{4}$ for $5 \mathrm{~h}$ at $55^{\circ} \mathrm{C}$. We added ${ }^{32} \mathrm{P}$-labeled probe and hybridized for $15 \mathrm{~h}$. We washed gels overnight in $2 \times$ sodium chloride/sodium citrate buffer and $0.1 \%$ SDS at $55{ }^{\circ} \mathrm{C}$ and exposed them to film. For denatured gel hybridization, we incubated gels in $1.5 \mathrm{M} \mathrm{NaCl}$ and $0.5 \mathrm{~N} \mathrm{NaOH}$ and then neutralized them in $3 \mathrm{M} \mathrm{NaCl}$ and $0.5 \mathrm{M}$ Tris, $\mathrm{pH}$ 7.4, before hybridization.

Cell culture and media. We grew BJ fibroblasts in a 4:1 mixture of Dulbecco's modified Eagle medium and M199 medium containing 15\% fetal calf serum and grew MRC5 fibroblasts in Dulbecco's modified Eagle medium containing $10 \%$ fetal calf serum. Cells were split 1:4 or 1:8 on reaching confluency. We introduced TERT and T-Ag into the cells as previously described ${ }^{26}$. For contact inhibition, we grew BJ cells to confluency and held them for $4 \mathrm{~d}$ or $4 \mathrm{wk}$, replacing medium every $2 \mathrm{~d}$. For stress exposures, we exposed BJ cells to $6 \mathrm{~Gy}$ or $12 \mathrm{~Gy} \gamma$-irradiation or treated them with the following drugs for $24 \mathrm{~h}: 6 \mu \mathrm{g}$ $\mathrm{ml}^{-1}$ doxorubicin, $100 \mathrm{mM}$ cisplatin, $150 \mathrm{mM}$ hydrogen peroxide, $25 \mathrm{mM}$ methyl-nitro-nitroso-guanidine, $1 \mu \mathrm{g} \mathrm{ml}^{-1}$ cycloheximide, $2 \mu \mathrm{g} \mathrm{ml}^{-1}$ actinomycin $\mathrm{D}$ or $2 \mathrm{mM}$ hydroxyurea. For hyperoxic growth conditions, we grew cells for 2 wk in $40 \%$ oxygen. For nutrient starvation, we grew cells in medium deficient of glucose or deficient in leucine and glutamine for $48 \mathrm{~h}$. None of the treatments resulted in a senescence-like phenotype, as determined by morphology and the absence of senescence-associated $\beta$-galactosidase staining (data not shown). We carried out senescence-associated $\beta$-galactosidase staining as previously described ${ }^{27}$.

Densitometric analysis. We processed scanned images using NIH Image software to assess signal intensity of each T-OLA product. To correct for the non-Gaussian skewness of the data, we log-transformed the relative intensity values and calculated geometric mean intensities of duplicate products using modified analysis of variance ${ }^{28}$. We tested values against a null hypothesis where the product intensities of each sample are equal to those of the first sample, allowing for a trend in mean intensity from small to large products. Estimated contrasts between samples were transformed to relative changes and confidence intervals.

\section{Acknowledgments}

We would like to thank E. D'Ambrosio for helpful advice regarding T-OLA and for sharing unpublished results, F. Barany for repeated helpful advice, T. de Lange and J. Griffith for plasmids and K. Yates, Y. Dor, J. Yang, R. Watnick, P. Gupta, H. Vaziri, S. Dessain and other members of R.A.W.'s laboratory for helpful comments, discussion and critical review of the manuscript. This work was supported by Merck/MIT (R.A.W.), the US National Cancer Institute (R.A.W.), an American Association for Cancer Research Postdoctoral Fellowship (S.A.S.), an EMBO Long-Term Fellowship (I.B.), the Dana Farber Cancer Institute (V.J.C.), the US National Cancer Institute Howard Temin award (W.C.H.), a Doris Duke Charitable Foundation Clinical Scientist Development Award (W.C.H.) and a Kimmel Scholar Award (W.C.H.). R.A.W. is an American Cancer Society Research Professor and a Daniel K. Ludwig Cancer Research Professor.

\section{Competing interests statement}

The authors declare that they have no competing financial interests.

\section{Received 23 January; accepted 19 February 2003.}

1. Rubin, $\mathrm{H}$. The disparity between human cell senescence in vitro and lifelong replication in vivo. Nat. Biotechnol. 20, 675-681 (2002)

2. Hayflick, L. The biology of human aging. Am. J. Med. Sci. 265, $432-445$ (1973).

3. Harley, C.B. et al. Telomerase, cell immortality, and cancer. Cold Spring Harb. Symp. Quant. Biol. 59, 307-315 (1994).

4. Wright, W.E. \& Shay, J.W. Historical claims and current interpretations of replicative aging. Nat. Biotechnol. 20, 682-688 (2002).

5. Harley, C.B., Futcher, A.B. \& Greider, C.W. Telomeres shorten during ageing of human fibroblasts. Nature 345, 458-460 (1990).

6. Bodnar, A.G. et al. Extension of life-span by introduction of telomerase into normal human cells. Science 279, 349-352 (1998).

7. Vaziri, H. \& Benchimol, S. Reconstitution of telomerase activity in normal human cells leads to elongation of telomeres and extended replicative life span. Curr. Biol. 8, 279-282 (1998).

8. Allsopp, R.C. \& Harley, C.B. Evidence for a critical telomere length in senescent human fibroblasts. Exp. Cell Res. 219, 130-136 (1995).

9. Zhu, J., Wang, H., Bishop, J.M. \& Blackburn, E.H. Telomerase extends the lifespan of virus-transformed human cells without net telomere lengthening. Proc. Natl. Acad. Sci. USA 96, 3723-3728 (1999).

10. Ouellette, M.M. et al. Subsenescent telomere lengths in fibroblasts immortalized by limiting amounts of telomerase. J. Biol. Chem. 275, 10072-10076 (2000).

11. Blackburn, E.H. Telomere states and cell fates. Nature 408, 53-56 (2000).

12. Karlseder, J., Smogorzewska, A. \& de Lange, T. Senescence induced by altered telomere state, not telomere loss. Science 295, 2446-2449 (2002).

13. Wright, W.E., Tesmer, V.M., Huffman, K.E., Levene, S.D. \& Shay, J.W. Normal human chromosomes have long G-rich telomeric overhangs at one end. Genes Dev. 11, 2801-2809 (1997)

14. Makarov, V.L., Hirose, Y. \& Langmore, J.P. Long G tails at both ends of human chromosomes suggest a $C$ strand degradation mechanism for telomere shortening. Cell 88, 657-666 (1997).

15. McElligott, R. \& Wellinger, R.J. The terminal DNA structure of mammalian chromosomes. EMBO J. 16, 3705-3714 (1997).

16. Huffman, K.E., Levene, S.D., Tesmer, V.M., Shay, J.W. \& Wright, W.E. Telomere shortening is proportional to the size of the G-rich telomeric 3'-overhang. J. Biol. Chem. 275, 19719-19722 (2000).

17. Blackburn, E.H. Switching and signaling at the telomere. Cell 106, 661-673 (2001).

18. Griffith, J.D. et al. Mammalian telomeres end in a large duplex loop. Cell 97, 503-514 (1999).

19. Henderson, E.R. \& Blackburn, E.H. An overhanging $3^{\prime}$ terminus is a conserved feature of telomeres. Mol. Cell. Biol. 9, 345-348 (1989).

20. Cimino-Reale, G. et al. The length of telomeric G-rich strand $3^{\prime}$-overhang measured by oligonucleotide ligation assay. Nucleic Acids Res. 29, E35 (2001).

21. Stansel, R.M., de Lange, T. \& Griffith, J.D. T-loop assembly in vitro involves binding of TRF2 near the 3' telomeric overhang. EMBO J. 20, 5532-5540 (2001).

22. Allsopp, R.C. et al. Telomere shortening is associated with cell division in vitro and in vivo. Exp. Cell Res. 220, 194-200 (1995).

23. Lingner, J., Cooper, J.P. \& Cech, T.R. Telomerase and DNA end replication: no longer a lagging strand problem? Science 269, 1533-1534 (1995).

24. Shay, J.W., Pereira-Smith, O.M. \& Wright, W.E. A role for both RB and p53 in the regulation of human cellular senescence. Exp. Cell Res. 196, 33-39 (1991).

25. Petersen, S., Saretzki, G. \& von Zglinicki, T. Preferential accumulation of singlestranded regions in telomeres of human fibroblasts. Exp. Cell Res. 239, 152-160 (1998).

26. Hahn, W.C. et al. Creation of human tumour cells with defined genetic elements. Nature 400, 464-468 (1999).

27. Dimri, G.P. et al. A biomarker that identifies senescent human cells in culture and in aging skin in vivo. Proc. Natl. Acad. Sci. USA 92, 9363-9367 (1995).

28. Liang, K. \& Zeger, S. Longitudinal data analysis using generalized linear models. Biometrika 73, 13-22 (1986). 